\title{
Kajian Kawasan Risiko Banjir Di Sungai Banjir Kanal Barat Dengan Mempertimbangkan Penurunan Muka Tanah (Land Subsidence)
}

\author{
Ivan Kurniawan ${ }^{1}$, Maria Marcellina Harnita Permatasari ${ }^{2}$, Budi Santosa ${ }^{3}$ \\ email: 1ivankur1997@gmail.com, ${ }^{2}$ mariamarcellinahp@gmail.com
}

Program Studi Teknik Sipil, Fakultas Teknik, Unika Soegijapranata, Semarang, Universitas Katolik Soegijapranata; Jl. Pawiyatan Luhur IV/1 Bendan Dhuwur Semarang 50234, 024-8441555

\begin{abstract}
Abstrak
Kota Semarang sebagai ibu kota Provinsi Jawa Tengah memiliki curah hujan tinggi yang mempengaruhi peningkatan muka air. Kota Semarang tak jarang dilanda bencana banjir karena sungai tidak lagi mampu menampung air sehingga melimpas ke daratan di daerah sekitarnya. Selain itu, penurunan muka tanah menjadi salah satu faktor terjadinya banjir di Kota Semarang. Oleh sebab itu, dilakukan pengkajian terhadap pemodelan kawasan risiko banjir pada Sungai Banjir Kanal Barat dengan menggunakan perangkat lunak HEC-RAS.

Tujuan utama dari peneltian ini adalah mengetahui tingkat risiko banjir pada area di sekitar Sungai Banjir Kanal Barat. Penelitian ini melakukan kegiatan perhitungan curah hujan harian maksimum, mencari hidrograf aliran dan melakukan pemodelan Sungai Banjir Kanal Barat dengan menggunakan metode unsteady flow.

Hasil analisis dari penelitian ini berupa peta risiko banjir kawasan Sungai Banjir Kanal Barat sebelum dan sesudah penuran muka tanah selama 10 tahun. Wilayah yang memiliki tingkat risiko banjir tertinggi dalam penelitian ini adalah Panggung Lor. Selama 10 tahun, peningkatan jumlah penduduk terpapar naik sebesar 5,52\% pada kawasan Sungai Banjir Kanal Barat.
\end{abstract}

Kata kunci : Melimpas, Penurunan Muka Tanah, HEC-RAS, Risiko Banjir

\begin{abstract}
Semarang city as capital of Central Java has high level of rainfall that affect the water level increase. Semarang city is not infrequently hit by flood because river cannot hold the water so it run off into the land in the surrounding area. Furthermore, land subsidence is one of the factor that cousing flood in Semarang city. Therefore, conducted an assessment of the flood risk area modeling in Banjir Kanal Barat river using software HEC-RAS.

The main purpose from this study is knowing flood risk level on area around the Banjir Kanal river. This research did maximum rainfall calculation, flow hydrographs calculation, and Banjir Kanal river with unsteady flow method.

Analysis result from this study are flood risk map Banjir Kanal Barat river area before and after land subsidence for 10 years. Area that has the highest level of the flood risk in this study is Panggung Lor. Over the past 10 years, the increase number of people exposed has increased by $5.52 \%$ in Banjir Kanal Barat river area.
\end{abstract}

Keywords: Run Off, Land Subsidence, HEC-RAS, Flood Risk 


\section{PENDAHULUAN}

\subsection{Latar Belakang}

Banjir merupakan salah satu fenomena atau bencana alam yang sering terjadi di semua negara di dunia. Selain itu ada beberapa hal yang menjadi penyebab terjadinya banjir, seperti durasi hujan yang sangat panjang dengan intensitas hujan yang tinggi, saluran- saluran drainase yang tersumbat dengan limbah-limbah dari penduduk sekitarnya.

Kota Semarang juga tak jarang dilanda bencana banjir. Seperti yang terjadi pada bulan Januari tahun 1990, Kota Semarang diterjang banjir bandang, bencana ini menghancurkan pemukiman, perkantoran, bahkan menewaskan ratusan warga. Hujan yang turun dengan deras mengakibatkan air dari Gunungpati dan Ungaran menerjang Kota Semarang, jalur Sungai Banjir Kanal Barat tidak mampu membendung arus air sehingga jebol dan terjadi banjir bandang di daerah sekitarnya.

Berdasarkan penjabaran di atas tersebut maka penting melakukan pengkajian terhadap pemodelan kawasan risiko banjir pada Sungai Banjir Kanal Barat dengan mempertimbangkan penurunan tanah dibantu dengan menggunakan software HEC-RAS.

\subsection{Rumusan Masalah}

Bencana banjir yang terjadi sangat merugikan bagi masyarakat setempat, oleh sebab itu perlu adanya penanggulanganpenanggulangan yang harus dilakukan untuk meminimalisir terjadinya bencana banjir lagi. Pemodelan kawasan risiko banjir pada Sungai Banjir Kanal Barat dinilai dapat menjadi salah satu bentuk dalam membantu penanggulangan bencana banjir di Kota Semarang.

\subsection{Tujuan Penelitian}

Pembahasan dalam tugas akhir ini memiliki tujuan-tujuan sebagai berikut: a. Mengetahui debit dan luas limpasan Sungai Banjir Kanal Barat,

b. Mengetahui jumlah penduduk terpapar sebelum terjadi penurunan tanah dan sesudah penurunan tanah selama 10 tahun,

c. Mengetahui tingkat risiko banjir pada area di sekitar Sungai Banjir Kanal Barat akibat penurunan tanah.

\section{TINJAUAN PUSTAKA}

\subsection{Hujan}

Hujan adalah sebuah proses terjadinya presivitasi dari uap air yang membentuk awan. Uap air yang berubah dan jatuh ke tanah dapat berupa air, salju, es, kabut, atau embun.

\subsubsection{Curah Hujan Area (Regional Distibution)}

Curah hujan area merupakan intensitas persebaran curah hujan yang dihitung dengan menggunakan acuan pada pengukuran curah hujan pada stasiunstasiun meteorologi dengan menggunkan metode tertentu (Asdak, 2007) antara lain Poligon Thiessen.

$d=\frac{A_{1} d_{1}+A_{2} d_{2}+A_{3} d_{3}+\cdots+A_{n} d_{n}}{A_{1}+A_{2}+A_{3}+\cdots+A_{n}}$

\subsubsection{Jenis Distribusi}

Dalam perhitungan hujan rancangan terdapat beberapa macam distribusi yang dapat digunakan, anatar lain sebagai berikut(Soemarto, 1999):

a. Distribusi Normal

$$
X_{T}=\bar{X}+\left(K_{T} \times S\right)
$$

b. Distribusi Log-Normal

$$
X_{T}=\bar{X}+\left(K_{T} \times S\right) \text {. }
$$

c. Distribusi Gumbel

$$
\begin{aligned}
& \mathrm{K}_{\mathrm{T}}=\frac{Y_{t-Y_{n}}}{S n} \ldots \ldots \ldots \ldots \ldots \ldots \\
& X_{T}=\bar{X}+\left(K_{T} \times S\right)
\end{aligned}
$$


d. Distribusi Log-Pearson III

$$
\begin{aligned}
& S= \\
& {\left[\frac{\sum_{i=1}^{N}\left(\log x_{i}-\log \bar{X}\right)^{2}}{N-1}\right]^{0,5}}
\end{aligned}
$$

$\mathrm{Cs}=$

$$
\frac{N \times \sum_{i=1}^{N}\left(\log x_{i}-\log \bar{X}\right)^{3}}{(N-1) \times(N-2) \times(S)^{3}}
$$

$$
\log X_{i}=\left(\log X_{i}-\log \bar{X}\right)^{2}+K_{T} \times \mathrm{S}
$$

\subsubsection{Uji Kecocokan Distribusi}

Uji kecocokan (the goodness of fit test) distribusi frekuensi dari sampel data terhadap fungsi distribusi peluang yang diperkirakan dapat menggambarkan/mewakili distribusi frekuensi tersebut diperlukan pengujian parameter (Soewarno, 1995).

a. Uji Chi Kuadrat

$$
X^{2}=\sum \frac{(E f-O f)^{2}}{E f}
$$

\section{b. Uji Smirnov}

$$
P[\max |\mathrm{P}(\mathrm{X})-P(X i)|] \Delta c r=a \ldots . .
$$

\subsubsection{Intensitas Curah Hujan}

Intensitas curah hujan merupakan perbandingan dari ketinggian atau kedalaman hujan per satuan waktu. Perhitungan intensitas curah hujan memiliki beberapa cara atau metode, antara lain adalah mononobe (Sanusi dan Syafruddin, 2016):

$I=\frac{R_{24}}{24}\left[\frac{24}{t}\right]^{\frac{2}{3}}$

\subsubsection{Hyetograph}

Hyetograph merupakan diagram yang menunjukan hubungan antara tinggi atau intensitas hujan dengan waktu. Dalam perhitungan hujan rancangan, diperlukan data perhitungan hujan rancangan yang didistribusikan menjadi hujan jam jaman. Salah satu model distribusi hujan yang dapat digunakan adalah Alternating
Block Method (ABM) yang merupakan cara sederhana untuk membuat hyetograph rancangan dari kurva Intensity-DurationFrequency (IDF).

\subsection{Risiko Banjir}

Risiko banjir merupakan dampak yang dialami saat terjadi kejadian banjir. Dalam menentukan indeks risiko bencana perlu mempertimbangkan nilai indeks dari kapasitas, kerentanan, dan bahaya. Skala indeks kerawanan dibagi ke dalam 3 kategori antara lain sebagai berikut (BNPB, 2012):

a. Rendah, dengan nilai $0,0<\mathrm{x} \leq 0,3$, apabila kepadatan jumlah penduduk terpapar kurang dari $500 \mathrm{jiwa} / \mathrm{km}^{2}$ dan jumlah penduduk kelompok rentan kurang dari $20 \%$

b. Sedang dengan nilai $0,3<\mathrm{x} \leq 0,6$, apabila kepadatan jumlah penduduk terpapar $500-1000 \mathrm{jiwa} / \mathrm{km}^{2}$ dan jumlah penduduk kelompok rentan $20 \%-40 \%$

c. Tinggi dengan nilai $0,6<\mathrm{x} \leq 1,0$, apabila kepadatan jumlah penduduk terpapar lebih dari $1000 \mathrm{jiwa} / \mathrm{km}^{2}$ dan jumlah penduduk kelompok rentan lebih dari $40 \%$.

\subsection{Penurunan Muka Tanah (Land} Subsidence)

Penurunan muka tanah adalah proses turunnya muka tanah yang didasarkan pada suatu data tertentu yang terdapat berbagai macam variabel penyebabnya. Penurunan muka tanah disebabkan oleh banyak hal, seperti hilangnya air tanah yang berakibat eksploitasi yang berlebihan, pembebanan pada permukaan, ketidakstabilan bidang 
tanah, bencana gempa yang berakibat pada rusaknya struktur tanah, dan lain-lain.

\subsection{Model Hidrologi}

Model hidrologi adalah sebuah sajian sederhana (simple representation) dari sebuah sitem hidrologi yang kompleks
(BR, 1993). Melalui model hidrologi dapat dipelajari kejadian-kejadian hidrologi yang pada gilirannya dapat digunakan untuk memprediksi kejadian hidrologi yang akan terjadi (Brooks et al, 1988).

\section{METODE PENELITIAN}

\subsection{Tahapan Penelitian}

Proses pengolahan data secara garis besar dilakukan secara bertahap dan digambarkan sebagai diagram alir pada Gambar 3.1.

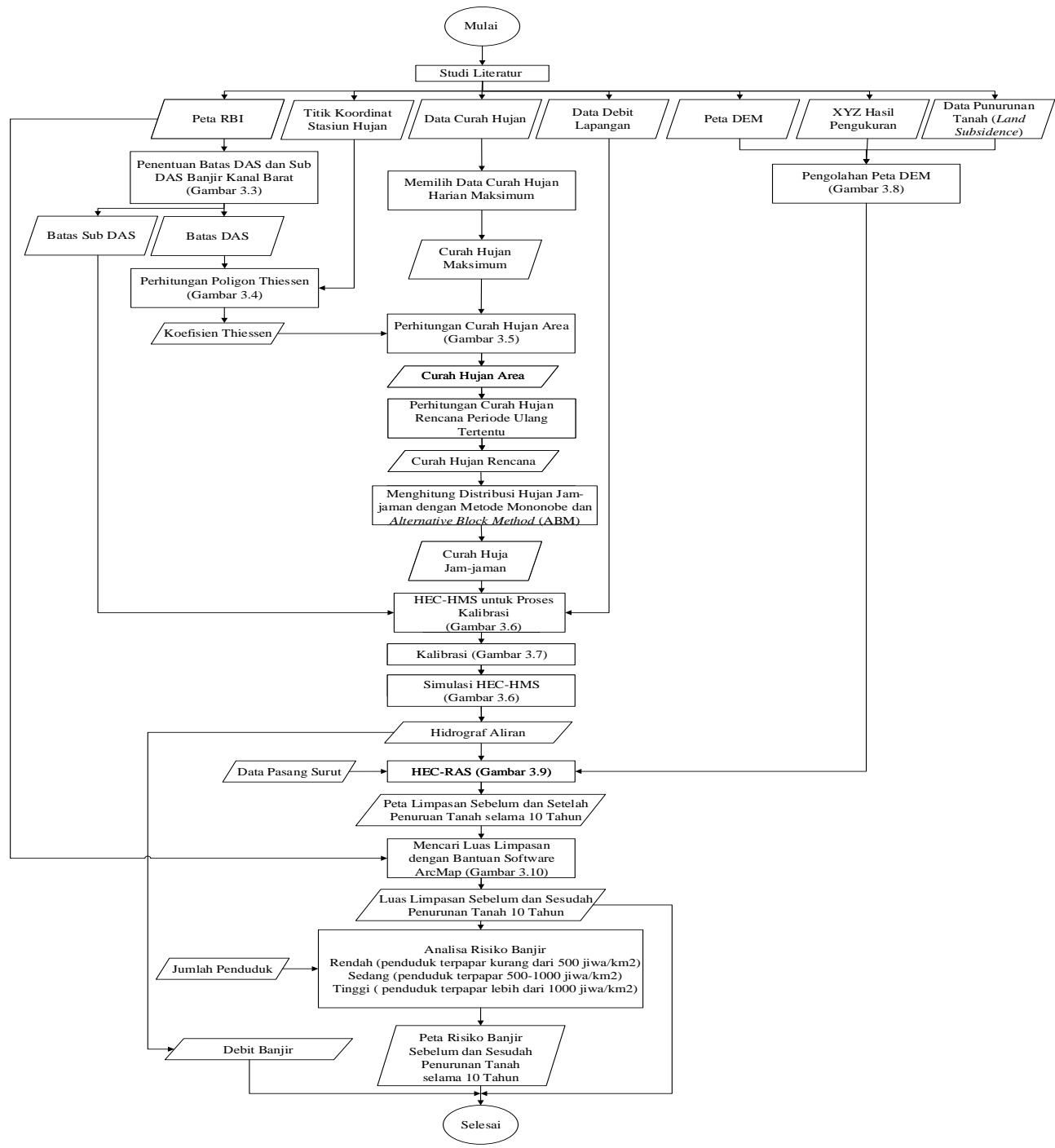

Gambar 3.1 Bagan Alir Penelitian 


\subsection{Tahapan Analisis}

Analisis data yang telah dikumpulkan dilakukan sesuai dengan tahapan yang telah ditentukan, yaitu:

1. Mempersiapkan data yang akan diolah

a. Curah hujan harian maksimum

b. Data geometri Sungai Banjir Kanal Barat

c. Peta topografi dan peta Digital Elevation Model (DEM) DAS Garang

d. Debit harian sungai Banjir Kanal Barat

e. Pasang surut air laut Kota Semarang pada saat bulan purnama

f. Jumlah penduduk Kota Semarang

2. Penentuan batas DAS dan membagi menjadi Sub DAS

3. Penentuan area Poligon Thiessen

4. Penentuan distribusi hujan rancangan

5. Penentuan parameter awal yang digunakan
a. Curve number $(\mathrm{CN})$
b. Impervious (\%)
c. Lag time.

6. Menghitung besar debit puncak banjir lapangan

7. Input data parameter awal kedalam software HEC-HMS

8. Kalibrasi parameter awal dan didapatkan debit puncak banjir simulasi

9. Penentuan parameter awal yang digunakan pada HEC-RAS
a. Pengolahan peta DEM
b. Nilai kekerasan Manning
c. Data aliran untuk analisis hidrologi

10. Input peta DEM, debit rencana, dan data pasang surut kedalam software HEC-RAS

11. Mencari luas limpasan dengan software bantu ArcMAp

12. Menghitung tingkat risiko banjir kawasan sungai Banjir Kanal Barat.

\subsection{Parameter Penelitian}

Terdapat beberapa parameterparameter yang digunakan dalam penelitian ini. Perhitungan hidrograf aliran menggunakan software HEC-HMS menggunakan parameter sebagai berikut:

1. Parameter Initial Abstraction, merupakan nilai air hujan yang terabstraksi ke dalam tanah

2. Parameter Curve Number, menentukan besarnya potensi retensi maksimum yang berpengaruh terhadap besar nilai hujan efektif dipengaruhi tipe tanah dan tata guna lahan

3. Parameter Impervious, merupakan luas daerah kedap air suatu wilayah DAS dengan nilai presentase tergantung penggunaan lahan

4. Dan Parameter Lag Time untuk setiap aliran sungai pada SudDAS dan Reach.

Terdapat beberapa parameter lain yang digunakan dalam perhitungan area limpasan menggunakan software HECRAS antara lain sebagai berikut:

1. Koefisien kekasaran Manning, dengan menentukan nilai Manning berdasarkan tipe salura

2. Kondisi batas, dengan mempertimbangkan kondisi batas sistem sungai (hulu dan hilir)

\section{PEMBAHASAN}

Hasil dari simulasi menggunakan software HEC-HMS berupa nilai debit 
puncak banjir sehingga dapat dimasukan sebagai input data pada software HECRAS bersama data pasang surut air laut pada saat bulan purnama dan peta DEM wilayah penelitian. Setelah dilakukan simulasi dengan 2 kondisi yaitu sebelum dan sesudah penurunan tanah maka diketahui limpasan Sungai Banjir Kanal Barat. Dalam kajian ini membandingkan tingkat risiko banjir sebelum dan sesudah terjadi penurunan tanah.

\subsection{Analisa Debit Puncak Banjir Hasil Output Software HEC-HMS}

Hasil dari simulation run didapatkan data output berupa peak discharge (debit puncak) dengan periode ulang tertentu yaitu 2 tahun, 5 tahun, 10 tahun, 25 tahun, dan 50 tahun.

Tabel 4.1 Debit Banjir Rencana Sungai

\begin{tabular}{|c|c|}
\hline \multicolumn{2}{|c|}{ Sengkarang } \\
\hline Periode & Debit $\left(\mathrm{m}^{3} / \mathrm{s}\right)$ \\
\hline 2 tahunan & 324,5 \\
\hline 5 tahunan & 582,1 \\
\hline 10 tahunan & 766 \\
\hline 25 tahunan & $1.006,8$ \\
\hline 50 tahunan & $1.190,1$ \\
\hline 100 tahunan & $1.375,7$ \\
\hline $\begin{array}{l}\text { Berdasark } \\
\text { at peningkat } \\
\text { periode } 2 \text { tah } \\
\text { nan. }\end{array}$ & $\begin{array}{l}\text { Tabel 4.1, dapat } \\
\text { debit puncak banjir } \\
\text { sampai periode } 100\end{array}$ \\
\hline
\end{tabular}

\subsection{Analisa Hasil Output Simulasi HEC- RAS}

\section{Eksisting}

Hasil dari simulation run didapatkan area limpasan sungai dan debit limpasan Sungai Banjir Kanal Barat dengan debit rancangan dengan periode ulang 25 tahun.

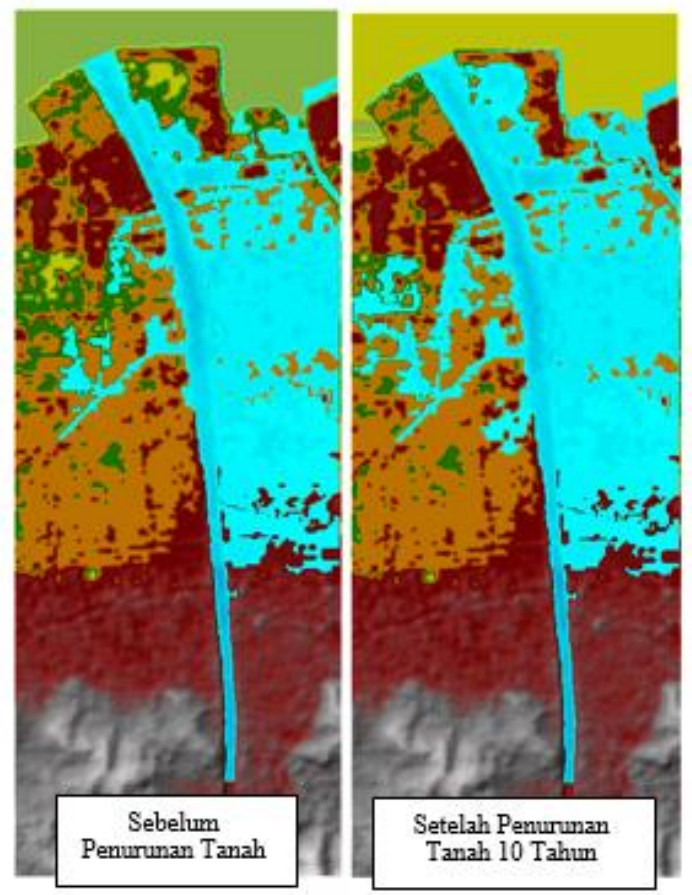

Gambar 4.1 Area Limpasan Sebelum Sesudah Penurunan Tanah Hasil output HEC-RAS menunjukan area limpasan pada Gambar 4.1. Luas genanangan akibat limpasan dapat dilihat pada Tabel 4.2.

\subsection{Risiko Banjir Sungai Banjir Kanal Barat}

Perhitungan risiko banjir didaptkan hasil peta risiko banjir pad Gambar 4.2. Tingkat risiko banjir pada saat sebelum dan sesudah penurunan tanah tidak terjadi perubahan walaupun jumlah penduduk erpapar mengalami perubahan tetapi tidak signifikan dan tingkat risiko banjir kawasan Sungai Banjir Kanal Barat dapat digambarkan ke dalam peta Pada Gambar 4.2. 


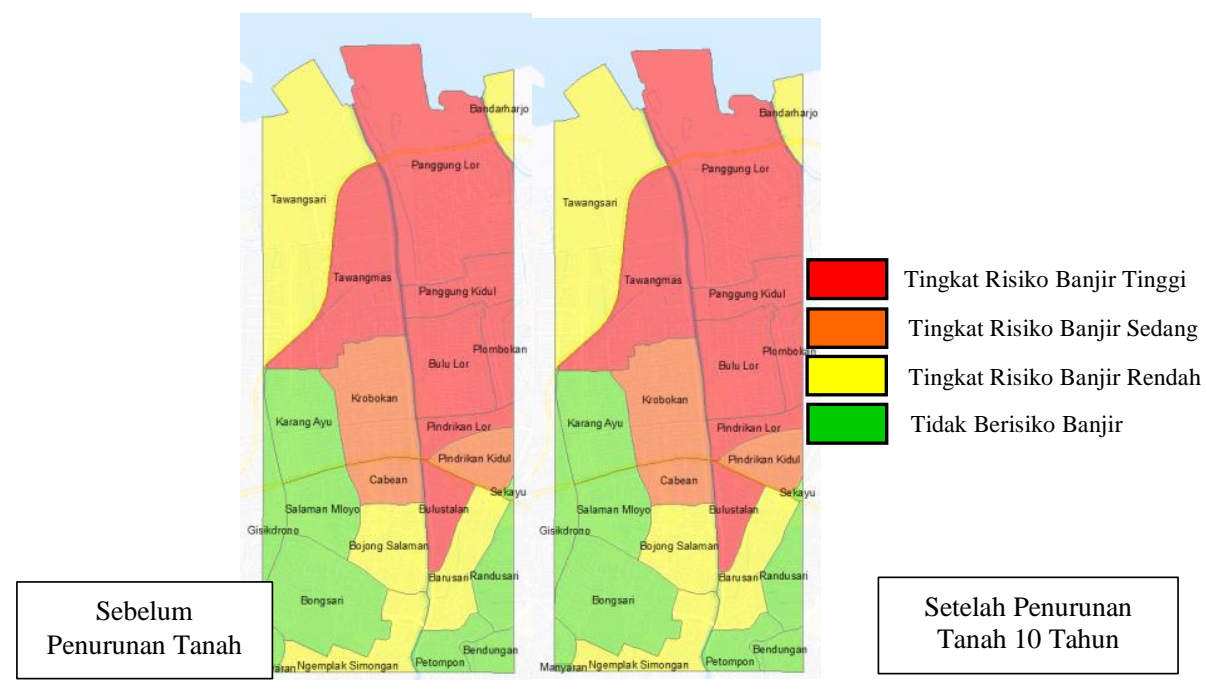

Gambar 4.2 Peta Tingkat Risiko BanjirSebelum dan Sesudah

Penurunan Tanah selama 10 Tahun

\section{PENUTUP}

\subsection{Kesimpulan}

Kesimpulan yang dapat diambil dari hasil analisis yang sudah dilakukan adalah sebagai berikut:

1. Debit banjir Sungai Banjir Kanal Barat periode ulang 25 tahun memiliki nilai debit puncak sebesar $1.006,8 \mathrm{~m}^{3} / \mathrm{s}$ dengan luas limpasan 3.461.784,092 $\mathrm{m}^{2}$ sebelum penurunan tanah dan 4.107.173,803 $\mathrm{m}^{2}$ sesudah penurunan tanah selama 10 tahun.

2. Jumlah penduduk terpapar sebelum terjadi penurunan tanah sebesar $53.799,580$ jiwa $/ \mathrm{km}^{2}$ dan jumlah penduduk terpapar sesudah penurunan tanah selama 10 tahun sebesar 56.770,376 jiwa/ $/ \mathrm{km}^{2}$, dengan peningkatan jumlah penduduk terpapar sebesar $5,52 \%$.

3. Tingkat risiko banjir pada kawasan penelitian yang terdiri dari 24 kelurahan dan tingkat risiko banjir tinggiterdapat pada kelurahan Bulu lor, Panggung Kidul, Pindrikan Lor,
Panggung Lor, Plombokan, Tawangmas, dan Bulustalan.

\subsection{Saran}

Saran yang dapat diberikan dari hasil analisis yang sudah dilakukan adalah sebagai berikut:

1. Perlu dilakukan normalisasi pada penampang Sungai Banjir Kanal Barat terutama pada bagian muara sungai (hilir), misalnya dengan pelebaran Sungai Banjir Kanal Barat,

2. Perlu dilakukan penanggulan terjadinya penurunan tanah terutama di daerah-daerah yang terkena limpasan dengan cara mengontrol pengambilan air tanah secara berlebih, membantasi beban bangunan di sekitar area yang mengalami penurunan tanah tinggi,

3. Perlu dilakukan maintenance atau perawatan berkala pada fasilitas sungai agar menjaga kualitas air dan meminimalisir terjadinya limpasan di sekitar Sungai Banjir Kanal Barat. 


\section{DAFTAR PUSTAKA}

Asdak, C. 2007. Hidrologi dan Pengelolaan Daerah Aliran Sungai. Gadjah Mada University. Press. Yogyakarta.

Badan Nasional Penanggulangan Bencana, 2012. Peraturan Kepala BNPB No. 02Tahun 2012 Tentang Pedoman Umum Pengkajian Risiko Bencana. Jakarta.

Sanusi, Wahidah dan Syafruddin. 2016. Statistika untuk Pemodelan Data Curah Hujan. Diakses dari https://www.semanticscholar.org/pap er/statistikauntuk-pemodelan-datacurah-hujan -SanusiSide/db660ec6e2ac2a711205ec214ca 6d2965dc52a20

Triatmodjo, B. 2010. Perencanaan Pelabuhan. Penerbit Beta Offset,. Edisi Pertama.

USACE. 2000. Hydrologic Modelling System HEC HMS Technical Reference Manual. US Army Corps of Engineer.

Wilson, E.M., 1979. Hidrologi Teknik. Penerbit ITB Bandung. 